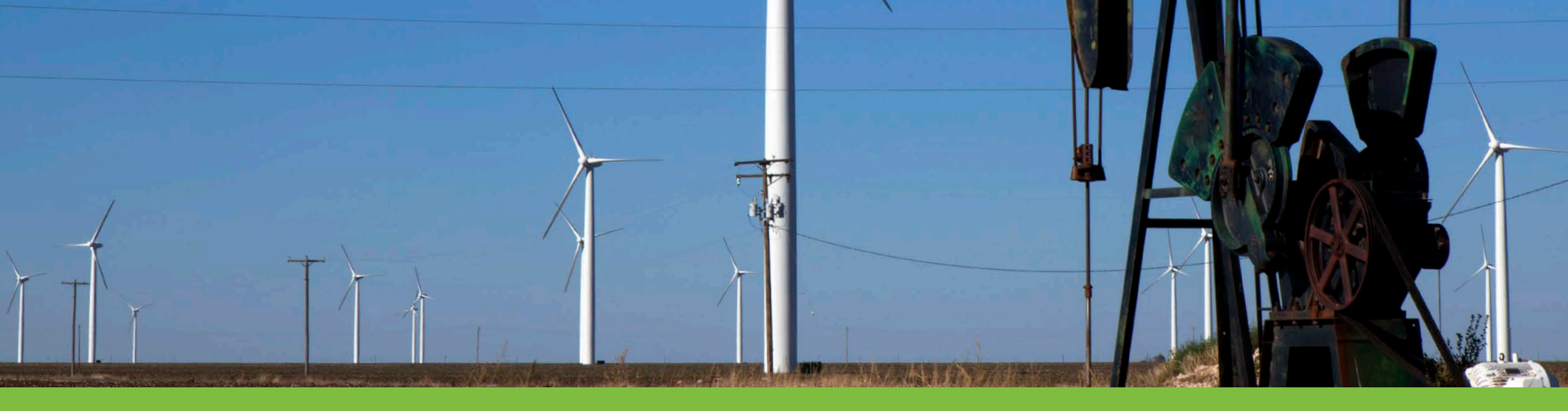

\title{
Integration of Clean Energy into Oil Field Operations
}

National Renewable Energy Laboratory • Emma Elgqvist, Ricardo Castillo, Emily Newes, and Jill Engel-Cox Conoco Phillips • Luis Zorrilla

\section{Summary of Findings}

Integrating clean energy into oil and gas operations could reduce emissions and maximize higher-value use of produced hydrocarbons. In this published study, analysts from the Joint Institute for Strategic Energy Analysis (JISEA) and the National Renewable Energy Laboratory (NREL) evaluated clean power technologies for an oil field in the Delaware Basin using NREL's REopt tool. The analysts evaluated different configurations of distributed energy resources based on the technologies available and the load they could satisfy, available land, and hypothetical carbon pricing. The analysis is part of a collaborative program with industry to understand sitespecific energy consumption and prices in the oil and gas supply chain and determine under what conditions clean energy options are economically attractive. This work was sponsored by a consortium including ConocoPhillips, Baker Hughes, Extraction Oil \& Gas, Kinder Morgan, and the Interstate Natural Gas Association of America Foundation.

\section{Snapshot}

- Smaller renewable energy technologies are cost-effective; larger systems generating $50 \%$ of the site's load offset significant amounts of carbon dioxide $\left(\mathrm{CO}_{2}\right)$ but at an added cost.

- For grid-connected systems, the low-cost industrial electricity rates ( $\$ 0.03$ per kilowatt-hour $[\mathrm{kWh}]$ ) paid by these facilities reduces the net present value of colocated renewable power installations beyond economic viability.

- A calculated cost of emissions reduction $\left(\$ / \mathrm{tCO}_{2} \mathrm{e}\right)$ based on renewable energy generated indicates that a cost of carbon of $\$ 7 / \mathrm{tCO}_{2} \mathrm{e}$ would result in a breakeven point for a renewable energy system generating $50 \%$ of the site's load (assuming the system could net meter excess generation).

- We performed a case study to understand the benefits of embracing microgrids as an enabling platform to increase energy resilience and optimize deployment of distributed energy resources (DERs) for grid and non-grid-connected systems.

These systems can help overcome operational challenges and progress toward sustainability goals when paired with renewable sources of energy.

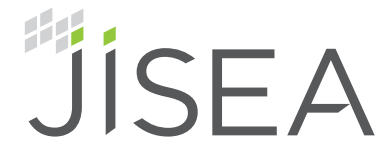

Joint Institute for Strategic Energy Analysis 
Increasing Importance of

Clean Energy in Oil and

\section{Gas Operations}

Oil and gas resources are expected to comprise a significant portion of our energy demand and economic output in the next decade. (U.S. Energy Information Administration 2021).

Prudent business practices, which are especially important in times with volatile oil prices, require minimizing product losses and reducing energy costs along the supply chain. Global pressure to address environmental concerns and the advantages of clean energy-reduced impacts on the environment, increased operational efficiencies, and conservation of oil and gas resources for the marketplace-are compelling the oil and gas industry to consider implementing clean technologies into their operations
(Domonoske 2021). In addition, the rapid decline in the price of clean energy technologies over the past decade (Figure 1) makes them more attractive than ever before, and the coupling of conventional generation with renewables could deliver the most feasible and economically attractive solution to reducing emissions.

One way to meet continued demand for oil and gas and the energy intensity required for oil field operations-while also meeting emissions reduction goals and minimizing environmental burdens-is to integrate clean energy technologies into oil and gas operations (Ericson, Engel-Cox, and Arent 2019). Incorporating clean energy technologies and otherwise reducing the amount of fossil fuels used in petroleum production, transportation, and refining processes has the potential to decrease both energy costs and greenhouse gas emissions, as well as to preserve oil and gas resources for their highest value uses.

In 2019, JISEA established a collaborative program to:

- Support the identification, development, and adaptation of highly reliable, cost-effective clean energy solutions for oil and gas operations

- Perform techno-economic analysis and site-specific optimization of combinations of renewable and conventional generation, storage, and energy conservation

- Demonstrate the most promising technologies for validation of performance in various field environments (while analyzing optimization scenarios), in partnership with industry.

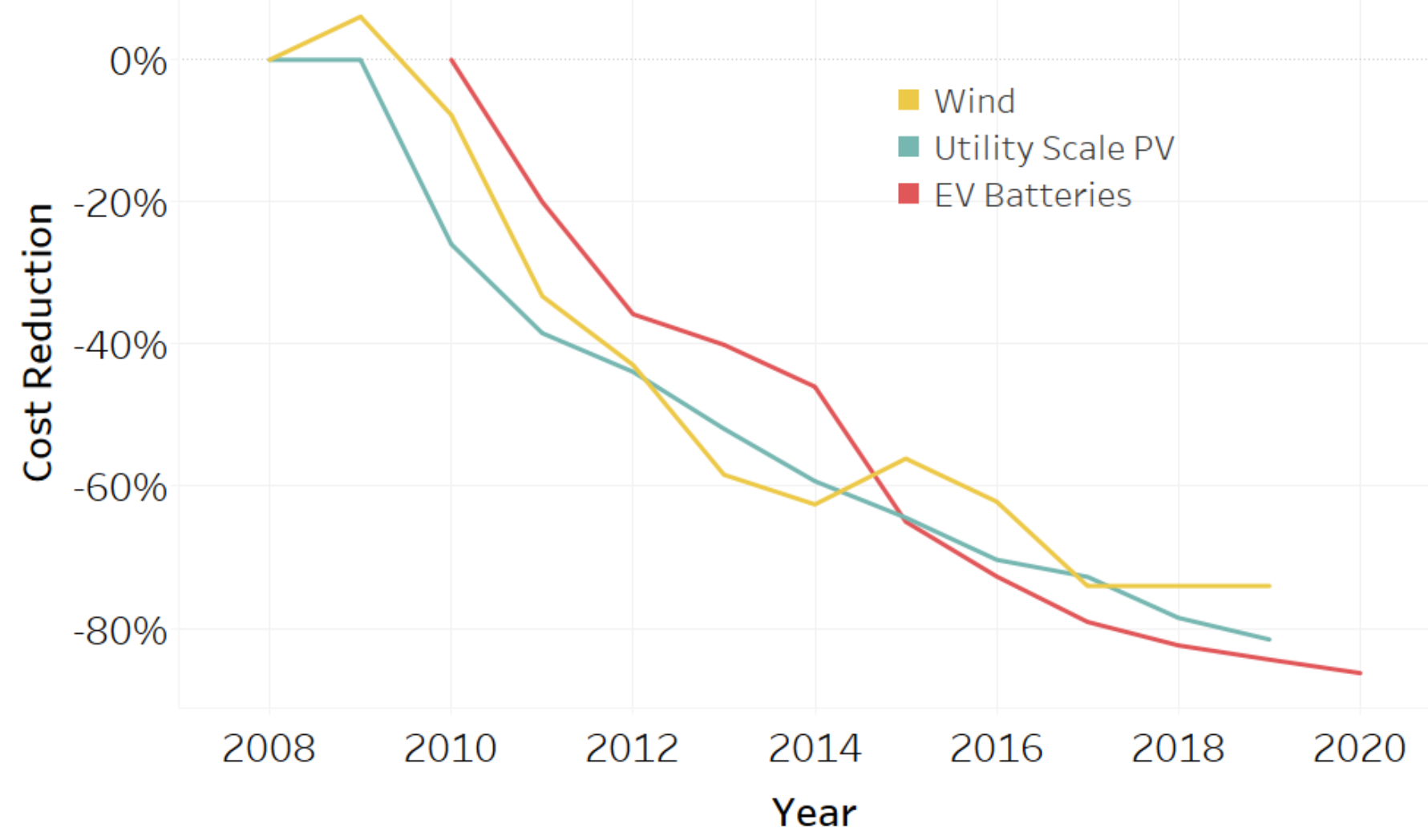

Figure 1. Clean energy technology percent cost reductions since 2008 Source: Natural Resources Defense Council 2021. EV is electric vehicle. 
Members of that consortium include ConocoPhillips, Baker Hughes,

Extraction Oil \& Gas, Kinder Morgan, and the Interstate Natural Gas

Association of America Foundation. As part of this program, and with supporting funding from the U.S. Department of Energy, the group has explored downstream (Krah et al. Forthcoming), midstream (Elgqvist et al. 2021), and upstream (Krah et al. 2020) clean energy, and energy resiliency goals. Specifically, the analysis evaluates solar photovoltaics $(P V)$, wind turbines, and energy storage for clean energy integration into oil and gas operations. The following content describes the techno-economic modeling and results from the upstream case, focusing on oil wells.

\section{Methodology}

To explore the techno-economics of renewable energy integration into oil and gas operations, JISEA/NREL analysts used NREL's techno-economic decision support model called REopt (NREL 2021). It was developed to optimize energy systems for buildings, campuses, communities, microgrids, and more. The tool recommends the optimal mix of renewable energy, conventional generation, and energy storage technologies to meet cost savings, resilience, and energy performance goals. Formulated as a mixed-integer linear program, REopt provides an integrated cost-optimal energy solution. An overview of inputs and outputs are shown in Figure 2. The technology assumptions used in REopt can be found in the appendix.
One key input to REopt is the oil field's electric load (typically as 15-minute or hourly data), which must be met by a combination of technologies in each time-step. For this analysis, the utility costs along with distributed solar PV, wind turbines, and battery energy storage systems (BESS) were considered. The model makes decisions about the most cost-optimal combination, size (possibly zero), and dispatch of technologies based on site goals, technology costs and incentives, and utility costs that could be avoided with distributed energy technologies.

\section{Case Study: Collection of Oil Field Operation in the \\ Delaware Basin}

The United States has a long history of oil exploration and production, with quantities reaching 12.8 million barrels

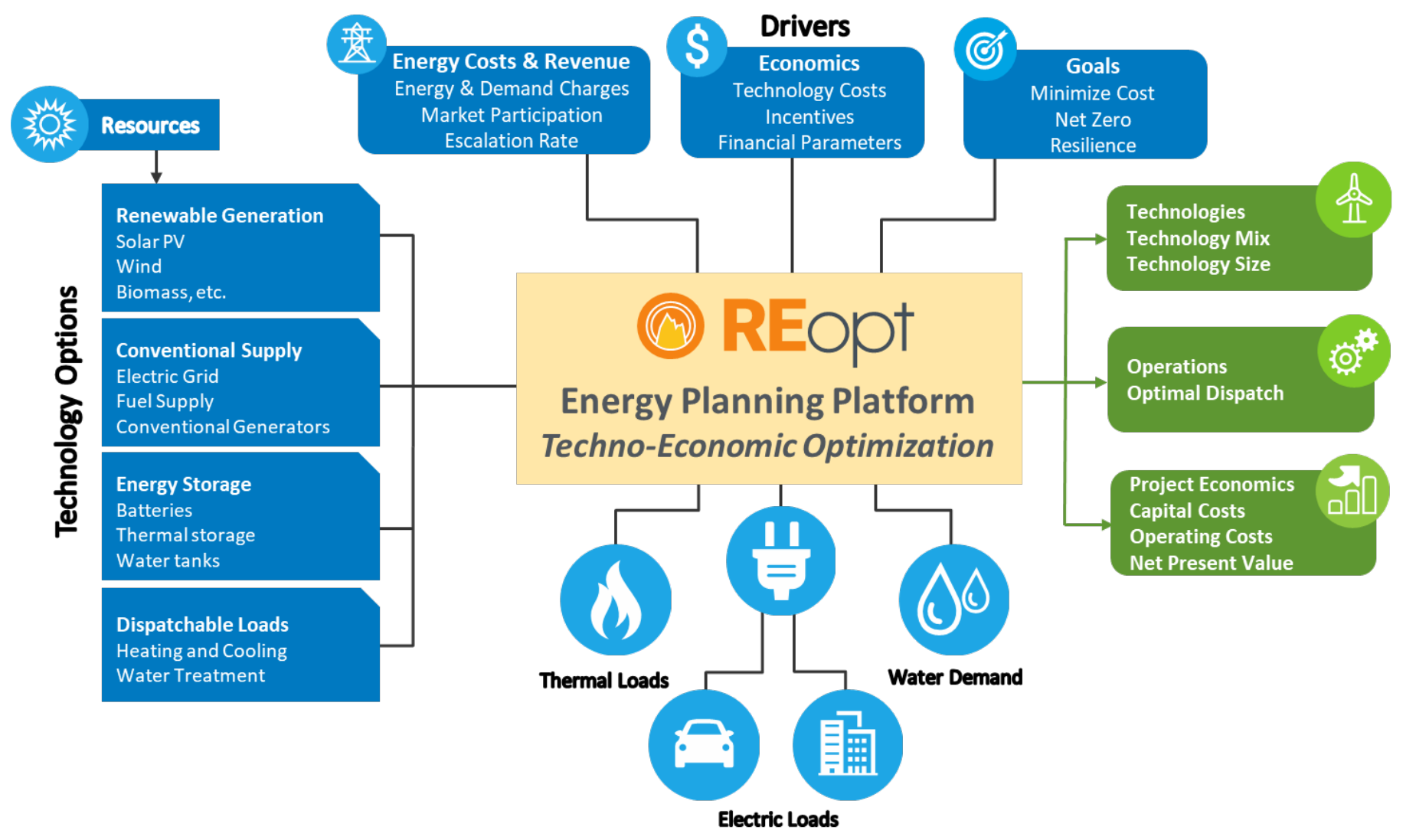

Figure 2. Overview of inputs and outputs for the REopt modeling platform

Source: National Renewable Energy Laboratory 


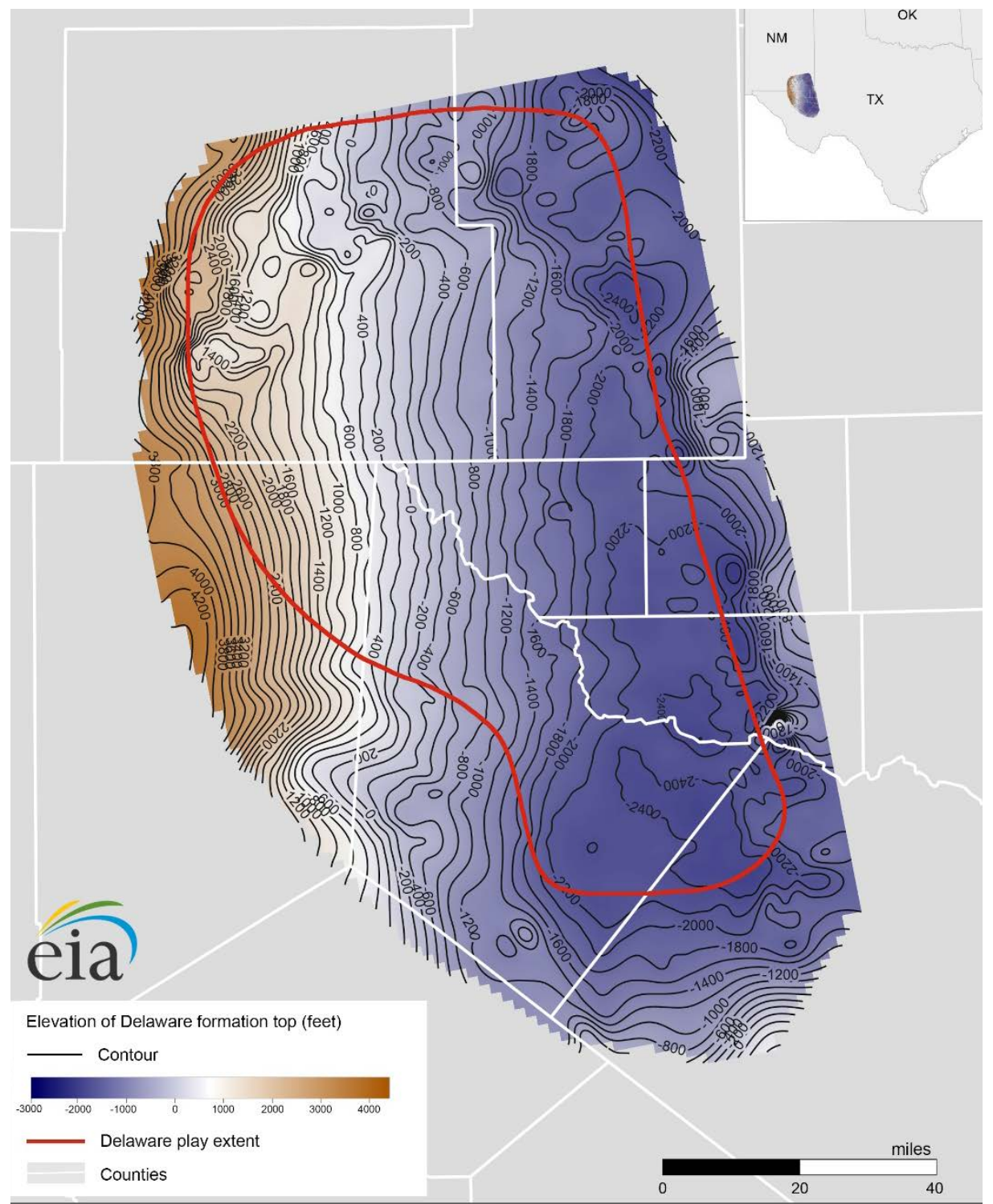

Figure 3. Delaware Basin map per day in December 2019 (U.S. Energy Information Administration 2020).

Currently, the number of productive wells in the United States is around 969,000. U.S. wells generally produce from 100 to 3,200 barrels of oil equivalent per day. Many recently drilled wells use horizontal drilling, which is the most productive drilling process (U.S. Energy Information Administration 2020). The Delaware Basin is part of the larger Permian Basin, an area of oil and gas production Southeast New Mexico and West Texas (Figure 3), that produces around 40\% of all U.S. oil. It is estimated that the Delaware Basin could produce a total of 46.3 billion barrels of oil (Railroad Commission of Texas 2021).

As a case study to explore energy options at upstream oil and gas sites, JISEA/NREL modeled clean energy options at a ConocoPhillips upstream production site in the Delaware Basin. The site has ample land that could be used for solar PV or other energy development, so the model was not constrained by land availability. Figure 4 shows the site's 15-minute-interval data for parts of 2019 and 2020. The original data (left) were rearranged, and missing

Source: U.S. Energy Information Administration 2019

15-Minute Interval Data Available

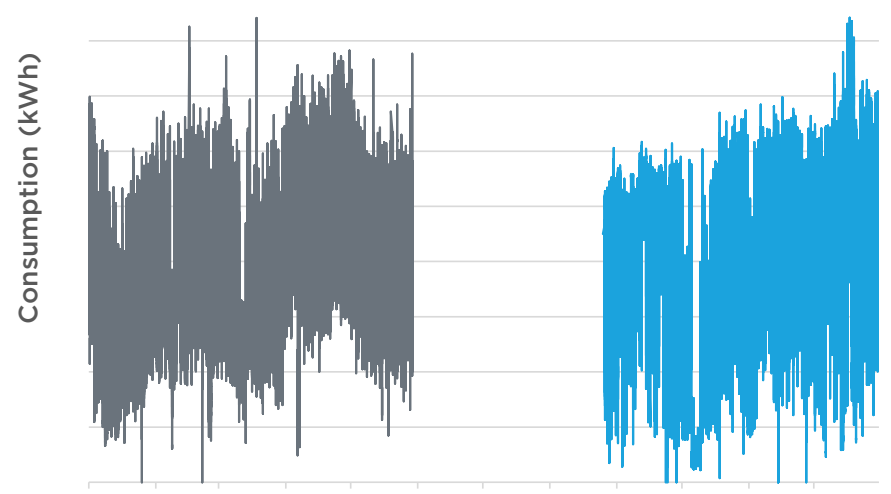

Jan Feb Mar Apr May Jun Jul Aug Sep Oct Nov Dec
15-Minute Interval Data for Modeling

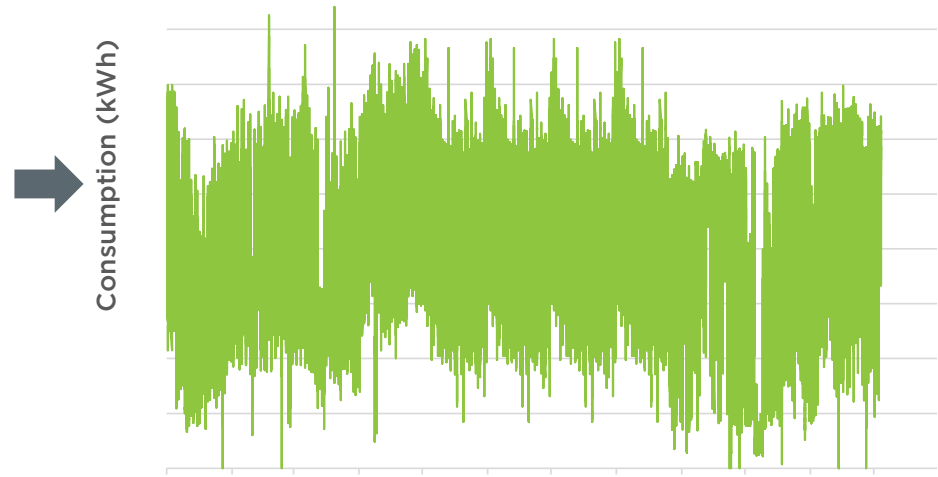

Jan Feb Mar Apr May Jun Jul Aug Sep Oct Nov Dec

\section{Usage 2019 Usage}

Figure 4. 15-minute interval energy consumption data for relevant feeder that supplies electricity to wells

Source: National Renewable Energy Laboratory 


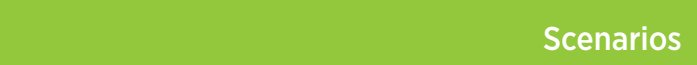

\begin{tabular}{l|l} 
1. Base Case & 2. No Net Metering
\end{tabular}

2B. $50 \%$

Renewable

PV size (kilowatt-DC)

Battery size (kilowatt)

Battery size (kilowatt)

Battery size (hours)

Wind size (kilowatt)

Total capital cost (dollars)

Electricity purchases (kilowatt-hour)

Percent renewable energy generated based on generation (\%)

Reduction in grid purchases (kilowatthour)

Annualized $\mathrm{CO}_{2} \mathrm{e}$ offset based on reduction in grid purchases $\left(\mathrm{tCO}_{2} \mathrm{e}\right)$

Cost of emissions reduction offset based on reduction in grid purchases $\left(\$ / \mathrm{tCO}_{2} \mathrm{e}\right)$

Renewable energy generated annually (kilowatt-hour)

Annualized $\mathrm{CO}_{2} \mathrm{e}$ offset based on renewable energy generated $\left(\mathrm{tCO}_{2} \mathrm{e}\right)$

Cost of emissions reduction based on renewable energy generated $\left(\$ / \mathrm{tCO}_{2} \mathrm{e}\right)$

Year 1 energy costs (dollars)

Year 1 demand costs (dollars)

Year 1 energy savings (dollars)

Year 1 demand savings (dollars)

Life cycle cost of electricity (dollars)

Net present value (dollars)
2A. Minimum Life Cycle Cost

\begin{tabular}{|c|c|}
\hline- & \\
\hline- & \\
\hline- & \\
\hline- & \\
\hline- & \\
\hline$\$ 0$ & $\$ 8,4 \varepsilon$ \\
\hline 338,858 & 323,52 \\
\hline $0 \%$ & 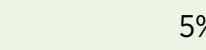 \\
\hline 0 & 15,33 \\
\hline 0 & \\
\hline 0 & \\
\hline 0 & $15,4 \mathrm{C}$ \\
\hline 0 & \\
\hline- & \\
\hline$\$ 10,369$ & $\$ 9,90$ \\
\hline$\$ 4,440$ & $\$ 4,37$ \\
\hline$\$ 0$ & $\$ 46$ \\
\hline$\$ 0$ & $\$ 6$ \\
\hline$\$ 195,417$ & $\$ 194,93$ \\
\hline$\$ 0$ & \\
\hline
\end{tabular}

6

53

3A. Minimum Energy Generation

Life Cycle Cost

91

8

91

2

0

0

2

0

0

1

0

$\$ 98,560$

212,586

$\$ 8,480$

323,522

$5 \%$

$50 \%$

126,268

15,332

125,520

6

53

$\$ 32.11$

169,471

15,402

169,429

6

71

6

$\$ 23.92$

$\$ 6,505$

$\$ 9,898$

$\$ 4,218$

$\$ 4,375$

$\$ 471$

$\$ 3,864$

$\$ 65$

$\$ 217,884$

$\$ 194,911$

$\$ 200,161$

$\$ 506$
71

$\$ 6.82$

$\$ 5.05$

$\$ 5,185$

$\$ 4,316$

$\$ 5,184$

$\$ 124$

$-\$ 4,745$

6 | Natural Gas - Electric Interface Study 


\section{Scenario 2B: Hourly Dispatch for 50\% RE Generation}

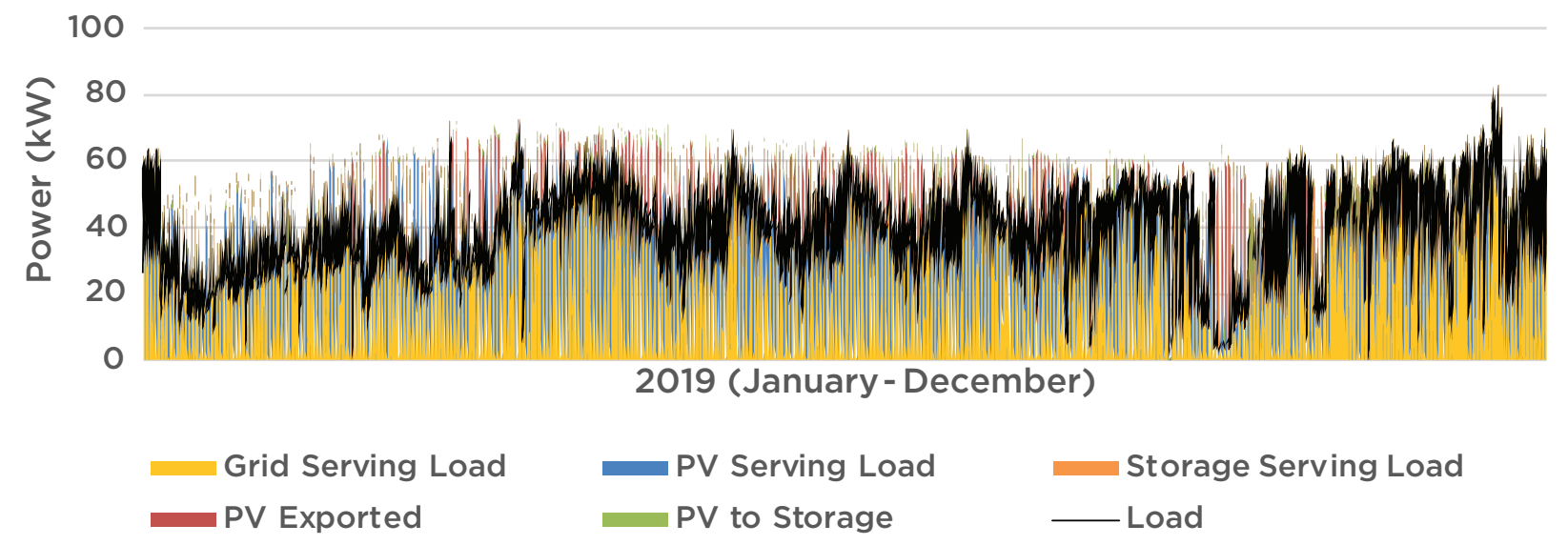

Figure 5. Hourly dispatch of solar PV and battery storage

Source: National Renewable Energy Laboratory

renewable energy technologies to provide carbon reductions. This breakeven point decreases to $\$ 6.82 / \mathrm{tCO}_{2} \mathrm{e}$ if the site can fully net meter the solar PV system. The impact of alternatively calculating these values is based on total on-site renewable generation, where the break-even point without and with net metering further decreases to $\$ 23.92$ / $\mathrm{tCO}_{2} \mathrm{e}$ and $\$ 5.05 / \mathrm{tCO}_{2} \mathrm{e}$ respectively.

If net metering is available (Scenario 3), the economics of the $50 \%$ renewable energy scenario improve significantly because the electricity that is generated above the load is compensated at the retail value; the 91-kW PV system would result in a net present value of $-\$ 4,745$, which is only a $2.5 \%$ increase in life cycle costs. The minimum life cycle cost solution (i.e., a smaller system) is not impacted because the resulting electricity generation rarely, if ever, exceeds the site load. Figure 5 shows how the solar PV and battery storage system would be dispatched throughout the year. PV generated above site load could be exported to the utility or curtailed.

\section{Microgrid Approach for Multiple Wells}

In addition to performing the REopt analysis, JISEA/NREL developed a high-level microgrid approach at the ConocoPhillips site that could be considered a road map of potential solutions on how to integrate and deploy microgrids into oil field operations. These microgrids could be deployed at the field scale and could support multiple well sites. Resiliency was the focus of this second assessment, and the objective was to increase the probability of surviving electrical outages and maintaining full operations. The technologies that were considered in this second assessment include:

\section{Solar PV paired with BESS}

2. Various infrastructure upgrades, such as additions to the communication network and reclosers that might be needed. A recloser is part of the system that islands the microgrid, or in this case connects the microgrid back to the main grid.
3. Natural gas generators that can use flare gas which would otherwise be burned: The U.S. Environmental Protection Agency has begun a very aggressive enforcement strategy of the New Source Performance Standards in $\S 60.18$ and National Emission Standards for Hazardous Air Pollutants in $\S 63.11$ with the intent to increase flaring efficiency and reduce venting. Therefore, this technology could transform an operational threat into a value stream opportunity, and it could help avoid significant penalties. One challenge for this technology is confirming there will be sufficient feedstock supply.

4. Diesel generators

5. Microgrid controllers.

Sizing these technologies would depend on many factors, such as the projected and desired period of continued operation during an electrical outage and the compensation scheme assigned to help make the business case. The existing system 


\section{0 kW PV, (1) 500 kW/500 kWh BESS, (2) 750 kW Dual-Fuel Generators}

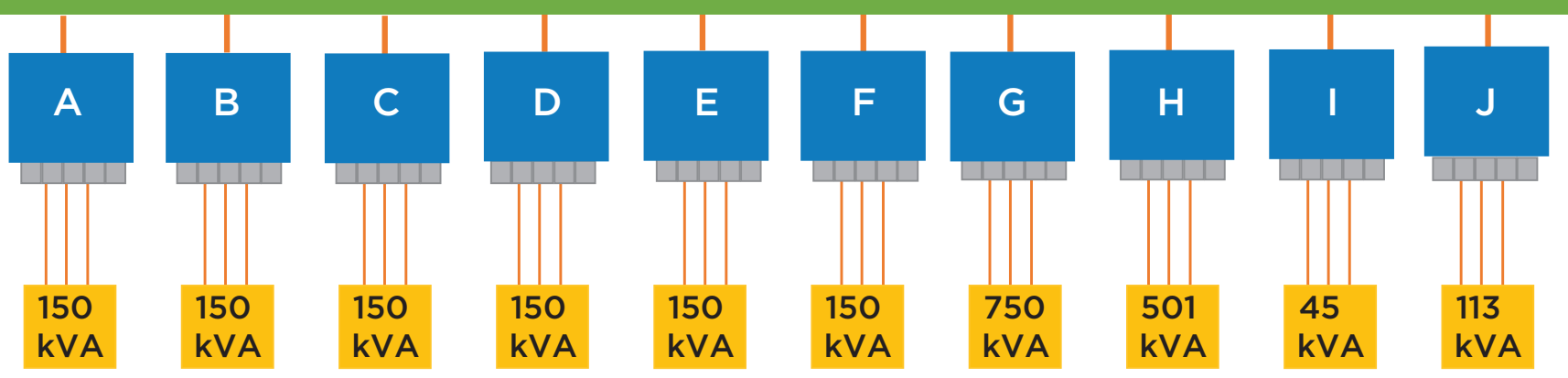

Figure 6. Schematic of existing electric distribution system and one potential resilient solution Source: National Renewable Energy Laboratory

includes a 21.6-kV feeder, about 10 substations that could potentially feed dozens of well sites-depending on operational and economic factorsthrough a distribution network simplified as in Figure 6. One potential system that could be considered consists of a central power plant rated at $1.5 \mathrm{MW}$ (two 750-kW diesel generators) paired with a 500-kW solar array and a 500 kW/500 kWh BESS. This system would be managed by a microgrid controller that would (1) enable the interoperability of the proposed generation mix in order to maximize the resiliency posture as well as (2) optimize the deployment of the proposed DER. Through either the existing communication network or network infrastructure, reclosers or remotely operated switches would allow the sectionalizing equipment required to bring in the microgrid sequentially and under various operating modes to enhance the resiliency of the system.

The system could enable movement from a grid-tied state to an islanded state via two main methods: uninterruptable power transition and blackstart. In the uninterruptable power transition, the microgrid controller and/or the BESS needs to react to the detection of a loss in utility power by providing these functions within a few cycles:
- Open the point of common coupling, separating the installation from the utility's power grid

- Operate the BESS in grid-forming mode to provide a voltage and frequency reference for the island; immediately, the microgrid controller will send a signal to the switchgear to enable the transfer of loads into the system.

- Regulate the PV to not exceed a specified threshold of the load and/or capability of the BESS system.

If the transition were successful, the oil field would not notice the transition or a loss in power, and most devices would continue operation during the transition. The BESS would cover the load requirement, and after the transition, the microgrid controller would start balancing sources and regulate the state of charge of the BESS. Note that it is acceptable for the PV to go offline to avoid instability in the system during the transition, as the focus is providing uninterruptable power to the installation loads until the diesel generator comes online. The PV can be reset and brought into operation after the transition as long as the ratio of the PV to the diesel generators is significantly small. Otherwise, the distribution system would require load tap changers to increase and stabilize the voltage.
The second possible transition from grid-tied state to island state is through a blackstart sequence. In this case, the installation's power grid has already gone down and there is no voltage on the 21.6-kV distribution system. The expected operation of the system at this point would be to:

- Open the point of common coupling, separating the installation from utility's power grid

- Open the breaker, separating the generator bus from the 21.6-kV bus so sources could be paralleled if required before energizing

- Start the BESS and/or generator in grid-forming mode to provide a voltage and frequency reference for the island

- Parallel other sources to the generator bus

- Close the breakers in a hierarchy sequence to start energizing the most critical and largest loads first.

The system could move from an islanded state to a grid-tied state via two main methods: closed transition and open transition. During a closed transition, the BESS and/or generator detects the grid voltage and frequency from the utility and synchronizes the island's voltage and frequency within a tight tolerance without interrupting power. 


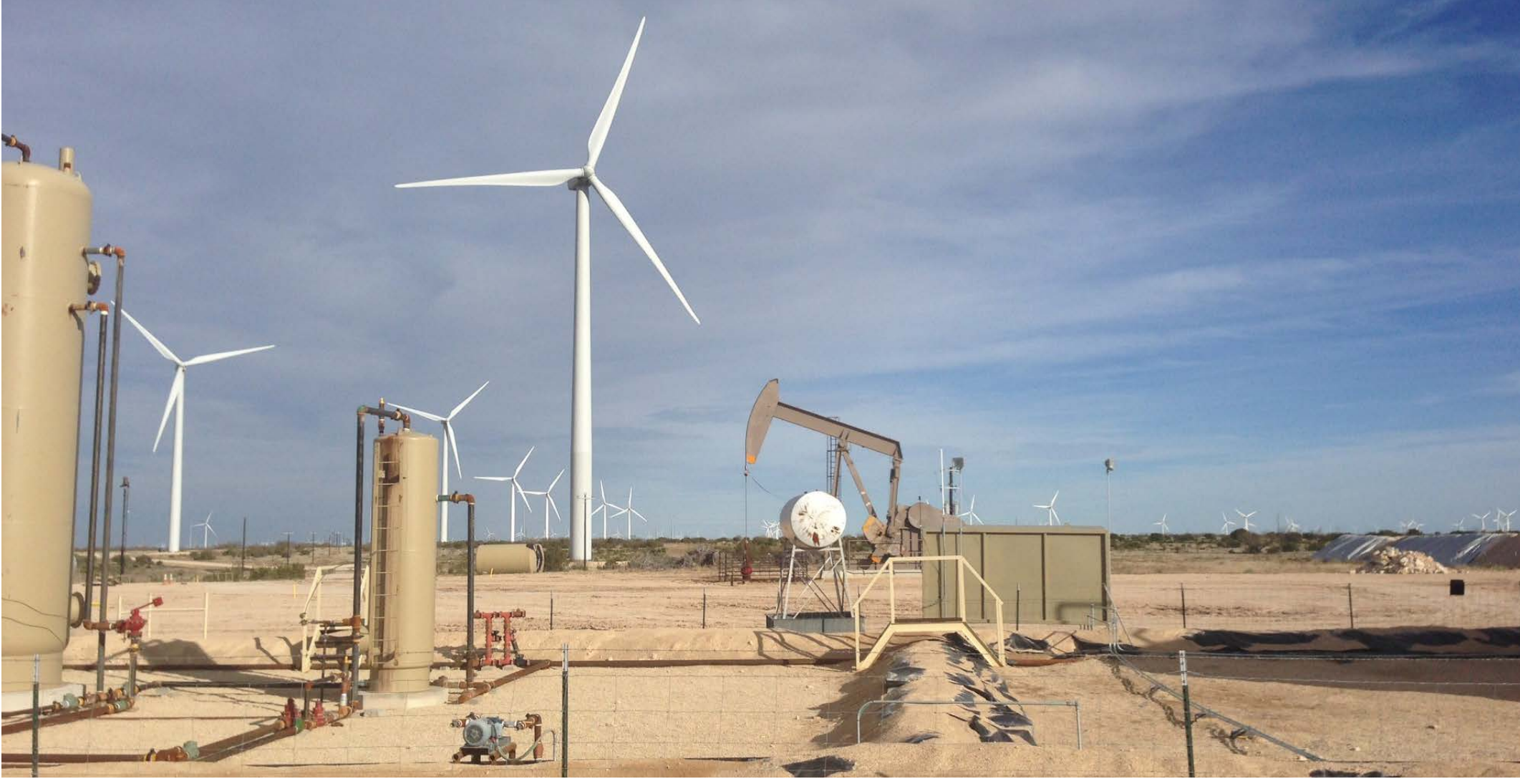

Oil field operations with wind turbines in the distance. Photo from istock 506613568

The main objective of the microgrid upgrades is to improve the resiliency posture and reduce electrical outages. Additionally, the microgrid can provide ancillary services such as an improved power quality, harmonics reduction, and power factor correction. Upon loss of utility power, the BESS could momentarily carry multiple feeders with dozens of well site loads connected. If utility power were not restored within 15 minutes, the diesel generators would start and would pick up the entire load. If the load were higher than the BESS capacity when utility power was lost, fast load shedding of noncritical facilities, or critical facilities with an uninterruptible power supply or its own source such as diesel generator, would begin. This would reduce the load and allow the BESS to come online until the diesel generators took over. With the potential diversity of DERs, different combinations of DERs could be deployed to maximize the value stream.
The intermittent nature of DERs is often cited as the major reason for limiting their broader deployment in highenergy intensity industries such as the oil and gas sector. However, the ongoing development of new standards is aimed at remedying these constraints. For example, IEEE 1547-2018 allows smart inverters to ride-through abnormal conditions of DERs. Such functionalities would address most of the concerns about the intermittent nature of DERs.

\section{Insights for Industry}

Quantifying - and raising awareness of the value of resiliency is paramount for the development, design, and operation of microgrids. Given increasing state and federal regulatory scrutiny, oil and gas operators could consider these novel approaches to decrease emissions and energy demand. Microgrids could become a highly effective tool kit that could not just help overcome operational challenges but help meet sustainability benchmarks.

BESS can help oil fields deal with the challenges resulting from the large proportion of inductive loads and power electronic equipment (variable frequency drives), which represent significant sources of low power factors and harmonics in the distribution system. Electric utilities commonly incur large financial penalties if these parameters fall outside their limits. So, a detailed study could assess a well site's needs to determine the appropriate technology design and the most cost-effective technology.

In this study, JISEA/NREL explored the potential for cost-effective clean energy implementation at an oil field in the Delaware Basin. The results indicate smaller renewable energy technologies are cost-effective; larger systems generating $50 \%$ of the site's load offset 
significant amounts of $\mathrm{CO}_{2}$ but at a fairly small added cost. JISEA/NREL calculated the cost of emissions reduction $\left(\$ / \mathrm{tCO}_{2} \mathrm{e}\right)$ based on renewable energy generated and found that this too could improve economics should they be monetized.

The oil field operation studied here benefits from low costs of grid electricity purchases, making the economics of renewable energy integration challenging. Sites in other areas of the country may have higher electricity rates, making renewable energy installation more profitable. Renewable energy technology costs continue to decrease across the country. Although there is variability in renewable energy resources across the United States, it is likely that the avoided cost of electricity (coupled with current or existing policy environments) could drive prioritization and implementation of clean energy projects. More specifically, the adoption of microgrids will provide two significant strategic advantages to the operations:

- The increased resilience will enable a higher chance to overcome electrical outages and operate independently from the electric utility, when needed.

- Microgrids are more likely to create higher value streams from DERs through an optimized dispatch strategy and the deployment of ancillary services.

Future adoption of microgrids could realize the intersection of operations and sustainability and leverage their shared goals. Taking full advantage of the approaches laid out in this study could enable a coherent sustainability strategy to complement and enhance operational requirements. Well sites have promising site-specific resources and conditions to make this approach a reality.

In the future, the REopt analysis could be expanded to cover more oil wells and land areas where larger PV plus battery energy storage systems could be developed and provide power to the market. This could allow assessment of an alternative business model and provide more value than net metering.

\section{References}

Domonoske, Camila. 2021. "Big Oil (Probably) Isn't Going Away Anytime Soon. But It's Definitely Changing." NPR. org (blog). June 8, 2021. https://www. npr.org/2021/06/08/1002448099/bigoils-transition-3-takeaways-on-how-theindustry-is-and-isnt-going-green.

Elgqvist, Emma, Emily Newes, Jill Engel-Cox, and Ricardo Castillo. 2021. "Clean Energy Integration in Natural Gas Compressor Station Operations." JISEA Research Highlight. Golden, CO: Joint Institute for Strategic Energy Analysis. https://www.nrel.gov/docs/ fy210sti/80540.pdf.

Ericson, Sean, Jill Engel-Cox, and Doug Arent. 2019. "Approaches for Integrating Renewable Energy Technologies in Oil and Gas Operations." White Paper NREL/TP-6A50-72842. Colorado, USA: The Joint Institute for Strategic Energy Analysis. https://www.nrel.gov/docs/ fy19osti/72842.pdf.

Krah, K., S. Ericson, X. Li, W. Olawale, R. Castillo, E. Newes, and J. Engel-Cox. Forthcoming. "Distributed Clean Energy Opportunities for Refinery Operations."
---. 2020. "Opportunities for Clean Energy in Natural Gas Well Operations." In 2020 IEEE International Systems Conference (SysCon), 1-7. https://doi. org/10.1109/SysCon47679.2020.9275853.

NREL (National Renewable Energy Laboratory). 2021. "REopt: Renewable Energy Integration and Optimization.” 2021. https://reopt.nrel.gov/.

Natural Resources Defense Council. 2021. "Revolution Now." NRDC. April 2021. https:// www.nrdc.org/revolution-now.

Railroad Commission of Texas. 2021. "Permian Basin." 2021. https://www.rrc. texas.gov/oil-and-gas/major-oil-and-gasformations/permian-basin/.

Roberts, Billy. 2016. "2013 Electricity Price." Open Energy Information. April 26, 2016. https://openei.org/wiki/File:2013_ Electricity_Price.jpg.

U.S. Energy Information Administration. 2019. "Delaware Formation Structure Map (Delaware Basin)." Maps: Oil and Gas Exploration, Resources, and Production. October 28, 2019. https://www.eia.gov/ maps/maps.htm.

--_. 2020. "The Distribution of U.S. Oil and Natural Gas Wells by Production Rate." Washington, DC: U.S. Department of Energy. https://www.eia.gov/petroleum/ wells/pdf/full_report.pdf.

World Resources Institute, and World Business Council for Sustainable Development. 2021. "Greenhouse Gas Protocol." 2021. https://ghgprotocol.org/.

---. 2021. "Annual Energy Outlook 2021." Washington, DC: U.S. Department of Energy. https://www.eia.gov/outlooks/ aeo/.

This work was authored by the Joint Institute for Strategic Energy Analysis (JISEA), operated by Alliance for Sustainable Energy, LLC, for the U.S. Department of Energy (DOE) under Contract No. DEAC36-08G028308. Funding provided by Kinder Morgan, the Interstate Natural Gas Association of America Foundation, Extraction Oil \& Gas, Baker Hughes, and ConocoPhillips. The views expressed herein do not necessarily represent the views of the DOE, the U.S. Government, or sponsors. 
Appendix

\section{Economic analysis assumptions}

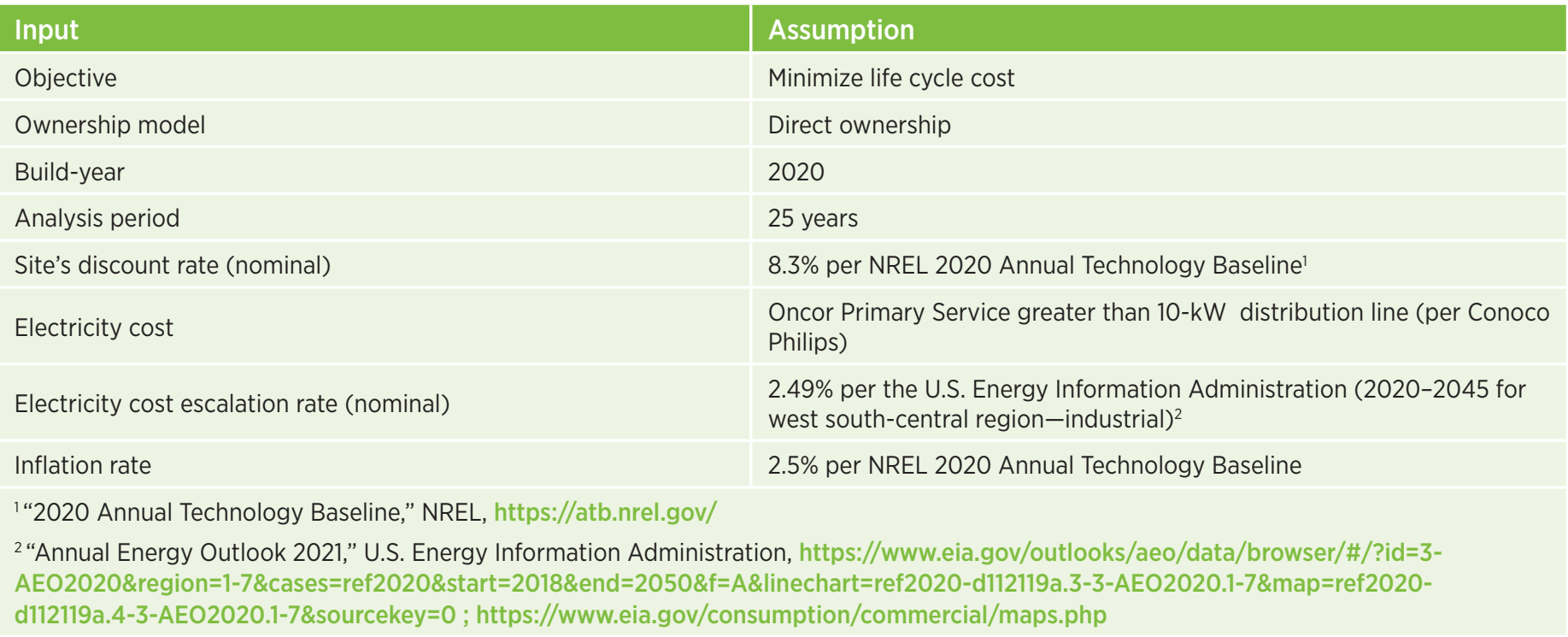

\section{Analysis assumptions for solar PV}

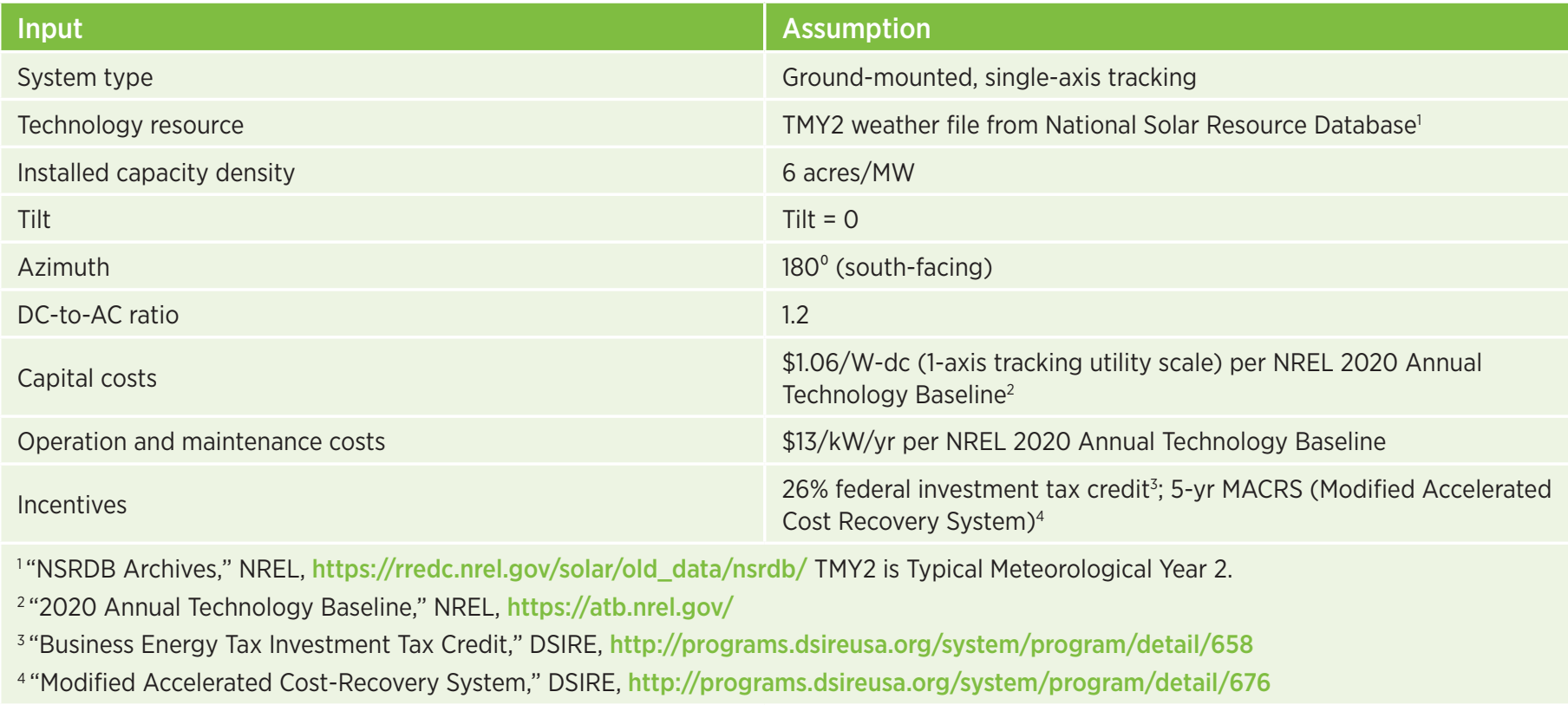

\section{Analysis assumptions for battery storage}

\begin{tabular}{|c|c|}
\hline Input & Assumption ${ }^{1}$ \\
\hline Battery type & Lithium-ion \\
\hline DC-DC round-trip efficiency & $89.9 \%$ \\
\hline Capital costs & $\$ 420 / \mathrm{kWh}+\$ 840 / \mathrm{kW}$ \\
\hline Replacement costs (year 10) & $\$ 200 / k W h+\$ 410 / k W$ \\
\hline
\end{tabular}




\section{Analysis assumptions for wind}

\begin{tabular}{|c|c|}
\hline Input & Assumption \\
\hline Technology resource & AWS Truepower database ${ }^{1}$ \\
\hline Installed capacity density & 30 acres/MW \\
\hline Operation and maintenance costs & $\$ 40 / \mathrm{kW} / \mathrm{yr}$ per NREL distributed wind cost analysis ${ }^{3}$ \\
\hline Incentives & 5-yr MACRS; federal production tax credit expired in $2019^{4,5,6}$ \\
\hline $\begin{array}{l}3 \text { "Assessing the Future of Distribute } \\
4 \text { "Business Energy Investment Tax } \\
5 \text { "Modified Accelerated Cost-Reco } \\
6 \text { "Renewable Electricity Production }\end{array}$ & $\begin{array}{l}\text { the-Meter Projects," NREL, https://www.nrel.gov/docs/fy17osti/67337.pdf } \\
\text { sireusa.org/system/program/detail/658 } \\
\text { ms.dsireusa.org/system/program/detail/676 } \\
\text { ms.dsireusa.org/system/program/detail/734 }\end{array}$ \\
\hline
\end{tabular}

\section{Analysis assumptions for emissions}

\begin{tabular}{|c|c|}
\hline Input & Assumption \\
\hline Region & Electric Reliability Council of Texas ${ }^{1}$ \\
\hline Total output emissions rate & $872.4 \mathrm{lb} . \mathrm{CO}_{2} \mathrm{e} / \mathrm{MWh} ; 5.1 \%$ grid loss $=0.42 \mathrm{tCO}_{2} \mathrm{e} / \mathrm{MWh}^{2}$ \\
\hline
\end{tabular}

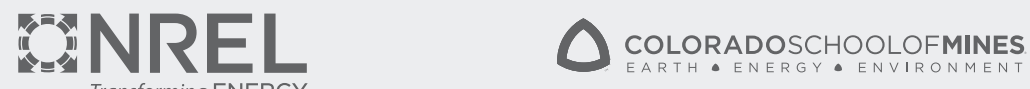

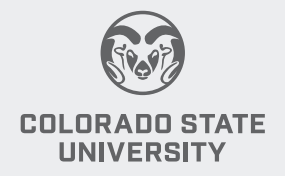

UNIVERSITY

JISEA is operated by the Alliance for Sustainable Energy, LLC, on behalf of the U.S. Department of Energy's National Renewable Energy Laboratory, the University of ColoradoBoulder, the Colorado School of Mines, Colorado State University, Massachusetts Institute of Technology, and Stanford University. 